\title{
REVIEW OF MANAGEMENT OF ART SERVICE DELIVERY FOR PEOPLE LIVING WITH HIVIAIDS IN NEPAL
}

\author{
Shrestha $L^{1}$, Subedi BK${ }^{2}$, Subedi $A^{3}$ \\ ${ }^{1}$ Epidemiologist, SAARC TB and HIVIAIDS Center, ${ }^{2}$ Director, FHD, Department of Health Services, MoH\&P, ${ }^{3}$ Master \\ Student Health Care Management, National Open College.
}

\begin{abstract}
HIVIAIDS epidemic has been gradually spreading in Nepal. It is one of the major public health problems of the nation. Treatment, Care and Support are the critical and essential components of the response to HIV infection and AIDS related morbidity in Nepal.

The cross sectional study was carried out at four public and three private Anti Retroviral Therapy (ART) sites during last 6 months of 2006 by selecting public ART sites based on the developmental regions of the country. From institutional set-up, human resources supply and availability of ART medicine's perspectives, the management practices of ART in Nepal is satisfactory. However, services need to be improved to make it more effective and efficient and client friendly, considering the standardization and sustainability of services.

Government has targeted to increase the number of certified service delivery points for provision of comprehensive treatment and care services in relation to HIVIAIDS. Hence, in order to achieve the targets with increasing the coverage there is a need to review the management process in established ART service delivery sites.
\end{abstract}

Key Words: HIVIAIDS, Nepal, ART

\section{Introduction}

Nepal is a country with immense cultural and geographical richness and diversity. And also home of some 23 million people. In Nepal HIVIAIDS was first diagnosed in 1988 in 4 patients ${ }^{1}$. Since then till now according to National Centre for AIDS and STD Control (NCASC) statistics, (16, November, 2007) there are 10369 people having HIV infection, out of this 1578 have developed AIDS and 449 people have died and estimated people with HIV are 70256 (2006).

HIVIAIDS epidemic has been gradually spreading in each and every corner of the

\section{Correspondence to:}

Dr Lochana Shrestha

Epidemiologist

SAARC TB and HIVIAIDS Center

Thimi Bhaktapur

E-mail: shresthalochana@yahoo.com country. It is one of the major public health problems of the nation. With consistently exceeding the prevalence of more than five percent in certain groups Injective Drug Users (IDUs) Migrants, the country has remained at a critical juncture of "Concentrated Epidemic" stage with looming threats of epidemic spreading to the general population. ${ }^{2}$

Treatment, Care and Support are more critical and essential components of the response to HIV infection and AIDS related morbidity in Nepal. This component will be more effective when the programme and activities are integrated into existing infrastructure both in public and private sectors. In Nepal access to Treatment, Care and Support services is still extremely low owing to the inadequate health delivery system, inaccessible private heath care and inadequate capacity for service delivery. 
Antiretroviral therapy has changed a fatal condition into a chronic and manageable disease and annual mortality rates of patients with AIDS are now well below $5 \%$ among those treated. ${ }^{3}$ ART also helps to mainstream the preventive activities and increase the utilization of preventive services.

In Nepal, from June 2003, Nava Kiran Plus being the leading organization, had started to provide ART to PLWHAs but Tribhuvan University, Teaching Hospital (TUTH), Kathmandu had been providing ART services to PLWHAs informally since 1998. Government developed guideline on ART and started providing ART services from 2004. Till end of 2006 there are seven ART sites at government hospitals and three community ART sites in private sector. By end of 2006 there are 560 HIV infected patients under ART treatment at public sector. 4

In recent years, in Nepal on one side HIV positives who need ART treatment are increasing and on the other hand Government is putting efforts to increase the sites to provide ART in easily accessible manner. Government has targeted to increase the number of certified service delivery points for provision of comprehensive treatment and care services with achievement of $80 \%$ of eligible PLWHA to be receiving ART by $2010 .{ }^{2}$

Hence in order to proceed to achieve the targets with increasing the coverage there is a need to review the management process in established ART service delivery sites. This will provide the background for upgrading the established sites and also for new establishment of service point to the level that would be effective for target people. This fact has led to under take this study to review the management process at different ART service delivery sites in Nepal.

\section{Materials and Methods}

This cross sectional study was carried out at 4 public ART sites - B.P. Koirala Institute of Health Sciences (BPKIHS) Dharan, in Eastern Region; Tribhuvan University, Teaching Hospital in Central Region; Western Regional Hospital in Western Region and Bheri Zonal Hospital, in Midwestern Development Region of Nepal and three private ART sites - Nava Kiran Plus (NK Plus), Maiti Nepal and SPARSHA Nepal during last 6 months of 2006. Nepal has 5 development regions and public ART sites are selected based on the region of the country. During the study period, ART sites at Far-western Region was at preparatory phase, so not selected for study. Among the private sites all the 3 sites which were documented were selected.

A semi-structured pre-tested questionnaire was used to collect the information in relation to coordination procedure, human resources and infrastructure of the sites, supply and availability of Anti Retroviral Drugs.

\section{Results}

In total 4 public ART sites, there were 346 HIV positive under treatment, among which highest $(46.5 \%)$ were at $\mathrm{WRH}$ and lowest (10.6\%) at Bheri Zonal Hospital. These four sites covered $61.1 \%$ of total HIV positives under treatment. Three private ART sites provided treatment for 194 HIV positives which constitute $34.6 \%$ of total HIV positives
Table 1 Number of PLWHA under Government ART sites

\begin{tabular}{|c|l|c|c|c|c|}
\hline SN & Name of Institutions & $\begin{array}{c}\text { No. of } \\
\text { PLWHA } \\
\text { receiving } \\
\text { ART }\end{array}$ & $\%$ & $\begin{array}{c}\text { PLWHA Per- } \\
\text { Day visit to } \\
\text { Institution }\end{array}$ & $\%$ \\
\hline 1 & BPKIHS, Dharan & 48 & 13.87 & 8 & 27.58 \\
\hline 2 & TUTH, Maharajgunj & 100 & 28.90 & 6 & 20.68 \\
\hline 3 & $\begin{array}{l}\text { Western Regional } \\
\text { Hospital, Pokhara }\end{array}$ & 161 & 46.53 & 10 & 34.50 \\
\hline 4 & $\begin{array}{l}\text { Bheri Zonal } \\
\text { Hospital, Nepalgunj }\end{array}$ & 37 & 10.69 & 5 & 17.24 \\
\hline & Total & 346 & 100.00 & 29 & 100.00 \\
\hline
\end{tabular}


under treatment. Nava Kiran (NK) Plus provided treatment to maximum number of HIV positives compared to other private sites under study. (Table $1 \&$ 2)

Table 2 Number of PLWHA under Private ART Sites

\begin{tabular}{|c|l|l|c|c|c|}
\hline $\mathrm{N}$ & $\begin{array}{l}\text { Name of } \\
\text { Institutions }\end{array}$ & $\begin{array}{l}\text { No. of } \\
\text { PLWHA } \\
\text { receiving } \\
\text { ART }\end{array}$ & $\%$ & $\begin{array}{l}\text { PLWHA } \\
\text { Per-Day } \\
\text { visit to } \\
\text { Institution }\end{array}$ & $\%$ \\
\hline 1 & $\begin{array}{l}\text { Nava } \\
\text { Kiran Plus }\end{array}$ & 150 & 77.31 & 12 & 50.00 \\
\hline 2 & $\begin{array}{l}\text { Maiti } \\
\text { Nepal }\end{array}$ & 22 & 11.34 & 5 & 20.83 \\
\hline 3 & $\begin{array}{l}\text { SPARSHA } \\
\text { Nepal }\end{array}$ & 22 & 11.34 & 7 & 29.16 \\
\hline & Total & 194 & 100.00 & 24 & 100.00 \\
\hline
\end{tabular}

There is found to be good coordination between private and public service sites with National AIDS control programme of country. For the utilization of the service and awareness regarding availability of service, private sites are under taking personal contacts with community where as public sites depend on National programmes awareness activities.

In relation to institutional set up, all public and private sites have doctors, consultation rooms and voluntary counseling rooms. Separate medical record room is present at all public service delivery sites, while at private sites only one institution has separate medical record room.

All private sites have separate general and isolated beds for ART but pubic sites do not have separate beds for ART. All public sites have laboratory facility where-as among private sites only one has simple lab facility. Two public sites (BPKIHS, WRH) have CD4 count facility. Central public sties (TUTH) utilized central level CD4 count facility at National Public Health Laboratory.(Table 3)
Table 3 The general and isolated beds in Government ART sites

\begin{tabular}{|l|c|c|c|c|c|}
\hline $\begin{array}{c}\text { Name of } \\
\text { Institution }\end{array}$ & $\begin{array}{c}\text { General } \\
\text { Beds }\end{array}$ & $\begin{array}{c}\text { Isolated } \\
\text { Beds for } \\
\text { ART }\end{array}$ & $\begin{array}{c}\text { Lab. } \\
\text { Services }\end{array}$ & $\begin{array}{c}\text { Lab. } \\
\text { with } \\
\text { CD4 } \\
\text { facility }\end{array}$ & $\begin{array}{c}\text { Radiol- } \\
\text { ogy } \\
\text { Servic } \\
\text { es }\end{array}$ \\
\hline BPKIHS & Yes & No & Yes & Yes & Yes \\
\hline TUTH & Yes & No & Yes & No & Yes \\
\hline WRH & Yes & No & Yes & Yes & Yes \\
\hline $\begin{array}{l}\text { Bheri } \\
\text { Z. H. }\end{array}$ & Yes & No & Yes & No & Yes \\
\hline $\begin{array}{l}\text { Nava } \\
\text { Kiran Plus }\end{array}$ & Yes & Yes & No & No & No \\
\hline $\begin{array}{l}\text { Maiti } \\
\text { Nepal }\end{array}$ & Yes & Yes & Yes & No & No \\
\hline $\begin{array}{l}\text { SPARSHA } \\
\text { Nepal }\end{array}$ & Yes & Yes & No & No & No \\
\hline
\end{tabular}

In relation to human resources, around 3-4 doctors allocated for ART at each public site are post graduate level and have clinical management training on ART, while practically only one or two of them are actively providing ART service. At these sites, 5-10 nursing staffs have clinical management training on ART, but it is found that only one or two of them are providing services effectively and others are active in other departments.

At private sites almost all nursing staffs have clinical management training on ART and they are providing services actively. At private sites, one or two doctors who worked there have MBBS or post graduate level degree and have clinical management training on ART except at one site (Maiti Nepal).

For all public sites sources of getting ARV drugs is government mechanism through NCASC and all keep the drugs stocks for two months and also maintain recording and reporting. Maiti Nepal depend on private donors for ARV drugs, while NK Plus depend on both private donor and NCASC for ARV drugs, SPARSHA Nepal get ARV drugs from NCASC only. Nava Kiran Plus mentioned that they will be able to provide ART medicines for 2 more years and Maiti Nepal can supply up to year 2010 A.D. Nava Kian 
Plus and SPARSHA are reporting monthly, while Maiti Nepal reports annually about the medicine. Both at public and private sites the process of getting ARV drugs is demand base. Regular supply of ARV drugs based on procurement mechanism adopted by Government for public sites and private donors for private sites.

Regarding ART committee, all public and private ART sites have separate ART committee to manage the ART services.

\section{Discussion and Conclusion}

All public and private ART sites have efficient institutional set-up. In case of the laboratory services, we found that only two public ART sites have CD4 count facility. There is essential to increase CD4 count facility.

Human resources are the people through which effective ART services are delivered. Staff are quite qualified and have clinical management training on ART, in all the public ART sites, and in some private ART none of doctors have clinical management training on ART. It is essential to make sure that service providers have clinical management training on ART.

Supply and availability of ARV drugs is very important aspect of ART service management. In all institutions supply and availability of medicine is good. However to maintain quality of drugs it would be better to make supply chain from one source for both private and public sites. This source should manage different fund generation for procurement and supply of ARV drugs for both private and public sites.

From institutional set-up, human resources supply and availability of ART medicine's perspectives, the management practices of ART in Nepal is satisfactory. However services need to be improved to make it more effective and efficient and client friendly. In addition standardization and sustainability of services need to be seriously considered, including expansion of ARV services.

\section{References}

1. Management of HIVIAIDS, Naveen Pess, Kathmandu, 1995, PP 1 - 10

2. National HIVIAIDS Strategy (2006-2011), Nepal, National Center for AIDS and STD Control, Ministry of Health and Population, October 2007

3. CASCADE Collaboration. Survival after introduction of HAART in people with known duration of HIV-1 infection. Lancet 355 , 1158-59(2000)

4. NCASC monthly reports on Cumulative HIV and AIDS Situation, December 2006. 